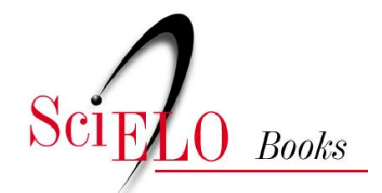

\title{
Maquiavel e seus primeiros leitores
}

\author{
Newton Bignotto
}

\section{SciELO Books / SciELO Livros / SciELO Libros}

BIGNOTTO, N. Maquiavel e seus primeiros leitores. In: PINTO, F.M., and BENEVENUTO, F., comps. Filosofia, política e cosmologia: ensaios sobre o renascimento [online]. São Bernardo do Campo, SP: Editora UFABC, 2017, pp. 89-113. ISBN: 978-85-68576-93-9. https://doi.org/10.7476/9788568576939.0006.

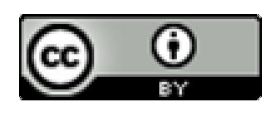

All the contents of this work, except where otherwise noted, is licensed under a Creative Commons Attribution 4.0 International license.

Todo o conteúdo deste trabalho, exceto quando houver ressalva, é publicado sob a licença Creative Commons Atribição 4.0.

Todo el contenido de esta obra, excepto donde se indique lo contrario, está bajo licencia de la licencia $\underline{\text { Creative }}$ Commons Reconocimento 4.0 . 
Possui graduação em Filosofia pela Universidade Federal de Minas Gerais (1980), mestrado em Filosofia pela Universidade Federal de Minas Gerais (1984), doutorado pela École des Hautes Études en Sciences Sociales (1989), pós-doutorado pela Université Paris Diderot (1997), pós-doutorado pela École des Hautes Etudes en Sciences Sociales (2005) e pós-doutorado pela Universidade de São Paulo (2013). Atualmente é professor titular da Universidade Federal de Minas Gerais. Tem experiência na área de Filosofia, com ênfase em História da Filosofia. Atua principalmente nos seguintes temas: Republicanismo, Maquiavel, Liberdade, Fundação. É autor de vários livros, entre eles: Maquiavel Republicano (1991); Origens do Republicanismo Moderno (2001); Maquiavel (2003); Republicanismo e Realismo (2006); As aventuras da virtude (2010); Matrizes do Republicanismo (2013). 


\section{MAQUIAVEL E SEUS PRIMEIROS LEITORES}

Newton Bignotto ${ }^{1}$

Falar da recepção imediata das obras de um autor do Renascimento cria de imediato um problema metodológico. Sabemos, como mostrou Claude Lefort (1972), que com o passar do tempo as leituras que são feitas de uma obra passam a influenciar diretamente os novos leitores e se incorporam de alguma maneira ao próprio texto, guiando o olhar dos que procuram compreender o pensamento do autor. A tarefa tem contornos diferentes de quando os "leitores" que procuramos estudar tiveram contato direto não apenas com a obra, mas com o próprio autor. Nesse caso a "recepção" é direta e se beneficia, ou é alterada, pelo contato com o autor do texto e com o conhecimento do contexto no qual se encontram os leitores e o escritor. Essa proximidade, no entanto, também traz

\footnotetext{
${ }_{1}$ Professor titular do Departamento de Filosofia da Universidade Federal de Minas Gerais (UFMG). Esse texto faz parte de minha pesquisa financiada por uma Bolsa de Produtividade do CNPq.
} 
problemas para o estudioso na medida em que, nesse caso, o elemento subjetivo, presente em toda interpretação, tem necessariamente um peso decisivo na elucidação do significado da obra. É claro que toda leitura de um escrito filosófico, ou outro, comporta uma dimensão subjetiva e também uma dimensão objetiva. Em que pese o desejo de muitos hermeneutas contemporâneos de suprimir ou diminuir ao máximo a dimensão subjetiva no ato de interpretar, parece-nos, na esteira do que escreve Lefort, e antes dele Merleau-Ponty (1968), que todo ato de compreensão de um escrito implica o leitor tanto quanto a obra. No caso de buscar entender o impacto imediato que uma filosofia teve nos leitores contemporâneos à elaboração da mesma, essas duas dimensões se tornam ainda mais evidentes e lançam um desafio para o estudioso.

Os escritos de Maquiavel não foram editados imediatamente após sua concepção, mas circularam na Itália, e mesmo fora dela, quando ele ainda estava vivo. Nossa preocupação nesse texto não é repertoriar as referências feitas ao secretário florentino nas primeiras décadas do século XVI, e nem mesmo apresentar um catálogo parcial de seus leitores da época. Vamos simplesmente procurar compreender como suas ideias foram recebidas e impactaram jovens italianos que conheceram o Secretário florentino e foram diretamente influenciados por ele. Trata-se, portanto, de um estudo de casos, que, sem que tenhamos a pretensão de transformá-los em síntese de todo uma geração, mostram os primeiros caminhos reflexivos que foram abertos pelo grande pensador renascentista. Para desenvolver nosso trabalho, escolhemos estudar os escritos de dois jovens que conheceram Maquiavel e que foram influenciados por suas ideias: Lodovico Alamanni e Antonio Brucioli. 


\section{Lodovico Alamanni}

Em 1512, depois do fracasso da resistência florentina face aos ataques dos espanhóis, os ottimati (parte da elite governante de Florença) aproveitaram-se da situação para tentar estabelecer um governo aristocrático, como já haviam feito em 1494. Gian Batista Ridolfi foi eleito gonfaloneiro (ALBERTINI, 1970, p. 20-21), o Consiglio degli ottanta foi reforçado e o Consiglio grande permaneceu funcionando como um símbolo da soberania popular (ANZILOTTI, 1969, p. 59). Todas essas manobras não foram suficientes, no entanto, para impedir o retorno dos Médici que, em 14 de setembro de 1512, tomaram o poder concentrando a gestão da cidade em novos órgãos a eles submetidos. Começa então para Florença um novo período de vida política, que acabou por destruir todas as instituições republicanas que haviam estado no centro de sua vida pública ao longo dos dois últimos séculos. Foi nesse período que a obra de Maquiavel foi elaborada (GILBERT, 1970).

Nesse contexto, uma literatura favorável aos Médici nasceu ao lado de textos que contestam seu domínio e sua pretensão de transformar Florença em um principado. Felix Gilbert foi pioneiro em mostrar como os amigos de Bernardo Rucellai recorriam à figura de Lourenço de Médici para tentar barrar a pretensão dos novos membros da família. Esse caminho foi importante para organizar a resistência por parte dos ottimati, mas era tributário das ideias dos humanistas cívicos, desenvolvidas no século anterior e, por isso, nem sempre levava em conta os novos dados do impasse político no qual se achava a cidade (SILVANO,1985). A grande transformação da cena política italiana no começo do século XVI impactou diretamente a maneira de se pensar a política dos 
florentinos. Uma boa dose de "realismo" passou a ser necessária para se compreender a derrota de 1512 (GILBERT, p. 95-113). Os elogios feitos a Lourenço de Médici, num primeiro momento, faziam alusão à sua capacidade de lidar com as disputas políticas internas. Pouco a pouco, no entanto, esse aspecto foi sendo deixado de lado e emergiu sua habilidade para lidar com os impasses diplomáticos. Essa mudança na imagem do Magnífico estava relacionada com o fato de que uma parte dos jovens, que se interessavam pela vida política da cidade, paulatinamente abandonou a ideia de que a família Médici deveria ser a dirigente do "partido dos ottimati" para se converter nos senhores de Florença por meio da criação de um principado (ALBERTINI, 1970, p. 20-44).

Homens como Paolo Vettori, Ghoro Gheri, ou ainda Lodovico Alamanni talvez não estivessem inteiramente conscientes do significado político de seu gesto de apoiar a criação de um principado em Florença. De alguma maneira, eles acreditavam que mesmo com o domínio dos Médici os aristocratas continuariam a ter um papel importante na vida política da cidade (Idem, p. 30). Foi nesse contexto que Maquiavel escreveu $O$ Príncipe e, como já foi mostrado por muitos intérpretes, tentou responder à angústia de muitos jovens que o conheceram e o escutaram, quando passou a frequentar as reuniões dos Orti Oricellari (SILVANO, 1985, p. 23-68).

Dentre esses jovens Lodovico Alamanni ocupa um lugar fundamental para nossos propósitos (Idem, p. 52-58). Filho de um partidário dos Médici, irmão de um adepto ferrenho do republicanismo dos humanistas do quattrocento, ele teve contato com Maquiavel ao longo da segunda década do século XVI, como prova uma carta do Secretário florentino datada de 17 de dezembro de 1517 (MACHIAVELLI, 1981, 
p. 382). Nessa carta fica claro que, apesar de os dois homens terem idades bem diferentes, eles eram próximos e Maquiavel parecia conhecer bastante bem o meio frequentado por Alamanni em Roma, onde se encontrava na ocasião da carta. Isso permitiu a Dionisotti afirmar que Alamanni foi um dos primeiros leitores/discípulos de Maquiavel (DIONISOTTI, 1980, p. 124). Em 1516, ele publicou dois discursos: "Sopra il fermare lo stato di Firenze nella devozione de' Medici" e "Illmo domino Alberto Pio, carpensi principi et caesareo oratori". ${ }^{2}$ Neles se vê a marca inequívoca do Príncipe, que também se encontra em outros jovens medicianos de sua geração.

Uma leitura atenta dos discursos de Alamanni mostra que algo havia mudado na literatura política florentina depois da catástrofe de 1512. Tratando-se de uma obra de caráter antirrepublicano não esperamos encontrar nela nem o tradicional elogio da liberdade, nem o argumento contra os tiranos. No entanto, o texto surpreende por adotar um caminho totalmente diferente dos speculum princeps dos séculos anteriores, que eram o modelo por excelência dos textos que faziam a defesa do governo principesco ou monárquico na Itália. $\mathrm{O}$ autor procura desde o início raciocinar levando em conta as diversas forças presentes no cenário italiano e que poderiam influenciar na luta dos Médici para dominar Florença (ALAMANNI, 1970, p. 34). Assim, depois de ter passado em revista todos os atores atuantes na cena italiana, Alamanni chega a uma conclusão que lembra a maneira de raciocinar de Maquiavel:

\footnotetext{
2 Ambos foram editados por Albertini (1970). Basta procurar entre as p. 376384, para o primeiro e p. 385-390, para o segundo. Todas as citações dos escritos de Alamanni foram retiradas dessa edição.
} 
Não existe príncipe algum, por mais poderoso que ele seja, cuja aliança seja uma garantia permanente de nossa vitória contra nossos inimigos, porque a fortuna é cambiante de tal maneira que por vezes é bom ser alemão, outras vezes espanhol e outras ainda francês (Idem, p. 378).

Mas a verdadeira influência de Maquiavel se revela no momento em que Alamanni mostra que sua principal preocupação é com a conservação dos principados recentemente conquistados. Não se trata de afirmar que o jovem florentino tratava de imitar Maquiavel de forma direta. A referência ao problema da conservação, no entanto, é uma indicação segura de que o pensamento do Secretário florentino era conhecido pelos jovens aristocratas e os influenciava de forma consistente. Essa coincidência de interesses não implicava que os jovens partilhavam as opiniões de Maquiavel. Alamanni reproduz alguns passos da argumentação de Maquiavel, procura argumentar de maneira serrada sobre as questões que lhe pareciam as mais importantes, mas, ao mesmo tempo, demonstra que estava longe de compreender o alcance das formulações do Secretário florentino.

Num primeiro momento, o jovem aristocrata alerta os Médici quanto aos poderes da fortuna: "porque a fortuna que tudo pode também podia alterar a situação presente" (ALAMANNI, 1970, p. 378). Ora, o perigo que ele vê no horizonte e que é evocado por meio da menção à deusa romana não é outro do que o persistente amor da liberdade por parte de muitos florentinos. Em uma passagem que lembra o quinto capítulo d'O Príncipe, ele afirma: "[...] se os florentinos encontrassem a ocasião de recuperar sua liberdade, eles a agarrariam de tal maneira, que eles procurariam se aliar a seus 
inimigos e os incitariam à guerra, pelo simples motivo de que isso lhes seria nocivo" (Idem, p. 378). Se na análise da incerteza que ronda todo poder, sobretudo tendo em vista a conduta de Piero de Médici e de Piero Soderini, Alamanni prova que ele compreendeu perfeitamente o sentido das observações de Maquiavel, quando ele aborda a questão da liberdade, mostra que estava longe de apreender o significado profundo da filosofia de seu mestre. Alamanni acredita que a liberdade era o centro da ação dos grupos que desejavam um retorno à situação anterior. Esses grupos são para ele "a seita do frade" - menção ao grupo dos adeptos de Savonarola - e os que "desejavam o conselho maior" - menção à facção republicana. Ora se ele tem razão em dizer que as forças políticas que se opunham aos Médici estavam no interior da cidade de Florença, mesmo se ele se engana quanto à força dos savonarolianos, pois acredita que "devem ser temidos por conta de suas fábulas e não por suas armas" (ALAMANNI, 1970, p.380), sua análise passa longe da maneira como Maquiavel pensava o amor da liberdade. Para Maquiavel, a liberdade era o objeto de desejo do "povo", por oposição aos "grandes". Esse desejo é sempre um desejo negativo, de não opressão, e, por essa razão, não pode ser extinto. Alamanni, ao contrário, enxergava no desejo da liberdade uma ânsia pela honra, típica de um certo grupo político da elite florentina (Idem, p. 382). Partindo da constatação empírica da existência de uma ou várias facções republicanas no interior de Florença, ele não consegue perceber o alcance real das análises maquiavelianas da liberdade. Se ele consegue fugir de certas ilusões típicas dos humanistas do quattrocento, está longe de compreender o alcance teórico e as exigências conceituais de uma leitura "realista" da política. Para ele, a simples menção à realidade imediatamente dada 
pela percepção, já era suficiente para fundar uma nova compreensão das relações sociais. ${ }^{3}$

Seguindo os passos de Maquiavel, ele procura compreender as divisões do corpo político em três grupos:

[...] o primeiro, por ser mais credível, inteligente e nobre, quer tomar o controle do Estado e governá-lo; o segundo se contenta com as honras da cidade, sem desejar governar; o terceiro fica satisfeito se não tem de pagar taxas muito elevadas e se a cidade é rica (ALAMANNI, 1970, p. 382).

Se essa divisão do corpo político pode parecer mais nuançada do que aquela bipolar proposta por Maquiavel, ela na verdade deixa de lado os propósitos teóricos mais profundos do pensamento maquiaveliano. Em Alamanni encontramos o que poderíamos chamar de descrição sociológica dos grupos políticos que atuavam na política florentina. Maquiavel sempre evitou reduzir a análise de uma dada situação política aos dados empíricos mais imediatos. ${ }^{4} \mathrm{~A}$ divisão do corpo político só tem sentido para ele porque revela o que há de universal nos conflitos da cidade. Tomada como "modelo histórico", ela perde sua força para se limitar a uma banal simplificação (DIONISOTTI, 1980, p. 111).

A mesma adulteração do pensamento de Maquiavel aparece quando Alamanni procura compreender o problema

\footnotetext{
${ }^{3}$ Gilbert foi pioneiro em mostrar o "realismo ingênuo" que está no centro do pensamento de muitos jovens da geração de Alamanni. Cf. Gilbert (1970, p. 120).

${ }^{4}$ Como exemplo, podemos pensar no terceiro capítulo d'O Príncipe e na análise da conquista de Milão. Ao mesmo tempo cabe recordar que em seu Discursus florentinarum rerum post mortem iunioris Laurentti, ele também faz referências aos grupos políticos presentes na cidade. Essa descrição, no entanto, é diferente daquela d'O Príncipe na medida em que tem um alcance meramente histórico. A esse respeito, ver Pancera (2010).
} 
do uso da força por parte do príncipe. Mais uma vez, os termos que ele usa e a maneira como apresenta a questão mostram claramente que ele tinha a obra maquiaveliana em mente quando escrevia:

Mas quero tomar outra via e digo que se Sua Excelência quer preservar o Estado, deve seguir um dos dois caminhos: ou formar uma milícia de cidadãos que possam defendê-la, ou deve se livrar de todos os que podem ou querem lhe fazer mal (ALAMANNI, 1970, p. 379).

Alamanni não hesita em dizer que a primeira solução é a mais desejável, pois ela mostra para os súditos a boa vontade e a humanidade do príncipe (Idem, p. 379). O príncipe (no caso os Médici) estando em posição de força pode contar que esse gesto lhe ajudará a manter o poder em Florença. A segunda opção, diz ele, não deve ser usada nem antes nem depois (Ibid., p. 379). Ela coloca o príncipe em posição delicada e em confronto com a tradição. Mesmo assim, Alamanni não deixará, em seguida, de raciocinar sobre o uso da força (Ibid., p. 380). À maneira de Maquiavel, ele coloca o problema em termos de cálculo de possibilidades, para depois explorar as consequências de cada uma das ações: "nós ficamos livres de duas maneiras: expulsando-os ou matando-os" (Ibid., p. 380). A primeira, diz ele, faz nascer uma forte oposição fora dos domínios territoriais do principado, o que ameaça sua estabilidade. Os exilados sempre podem recorrer a outros príncipes para tentar derrubar o regime instalado (ALAMANNI, 1970, p. 380). A segunda deve ser recusada sem ambiguidade. Primeiro porque um príncipe que queira ter uma boa imagem junto a seus súditos não pode ter as mãos sujas com seu 
sangue (Idem, p. 380). Em segundo lugar, ele observa que o massacre dos cidadãos só suscitaria o ódio do povo, que estaria mais do que nunca disposto a trocar de governante. ${ }^{5}$

Essa análise permite ao mesmo tempo aquilatar o impacto das ideias de Maquiavel na juventude florentina e a distância que os separava (ALBERTINI, 1970, p. 34). Fascinados pela ideia de força, eles buscaram refletir mais profundamente sobre seu significado para a vida política. Para muitos deles, o uso simples e puro da força era algo próprio dos tiranos. Procurando dar "conselhos" válidos para os Médici, jovens como Alamanni procuravam ao mesmo tempo tirar as lições do pensamento do Secretário Florentino e ficar próximos da tradição, sem notar a contradição que isso implicava. Para ele a força era a expressão da grandeza do príncipe e a violência um sinal de fraqueza do tirano. Nunca lhe ocorreu que o verdadeiro desafio teórico para o pensador da política é o de compreender os laços que aproximam e ao mesmo tempo diferenciam força e violência. Nesse sentido, o elogio a Lourenço, o Magnífico, serve para mostrar o fundo de seu pensamento, que tenta encontrar o caminho para recuperar a antiga grandeza da família Médici num contexto totalmente modificado (GILBERT, 1938).

Os intérpretes que desde a obra pioneira de Allan Gilbert procuraram aproximar Maquiavel da literatura dos "espelhos dos príncipes" acabam desconhecendo o caráter revolucionário de seu pensamento. Quando pensamos nos poucos capítulos d'O Príncipe aos quais fizemos referência e às análises de alguém como Alamanni, que conheceu pessoalmente

\footnotetext{
${ }^{5}$ Opomo-nos à interpretação de Albertini que, comentando a mesma passagem, afirma: "In modo machiavellico, a dir poco, egli soppesa le possibilità si adotar ela prima soluzione e giunge ala conclusione che l'impiego della violenza è anacronistico e inattuabile" (ALBERTINI, 1970, p. 36).
} 
Maquiavel e o frequentou, damo-nos conta de que ele tinha grande dificuldade para transmitir suas ideias, mesmo para os jovens que por elas se interessavam. Uma coisa era compreender no plano prático as dificuldades dos novos tempos, outra coisa muito diferente era entender que a nova maneira de pensar a política não significava apenas uma breve crítica aos aspectos da tradição, fosse ela a dos humanistas do século anterior, fosse ela a tradição do pensamento cristão. Os jovens florentinos ficaram fascinados pela filosofia maquiaveliana, mas procuravam resumi-la a umas poucas fórmulas, sem levar em conta seu aspecto revolucionário (DIONISOTTI, 1980, p. 142).

\section{Antonio Brucioli}

Antonio Brucioli interessa-nos porque permite-nos aprofundar o estudo a respeito das relações de Maquiavel com a juventude florentina de seu tempo. Embora não saibamos exatamente quando ele começou a frequentá-los, em particular nas reuniões que aconteciam nos chamados Orti Oricellari, não resta dúvida de que sua presença nesse lugar foi marcante para muitos de seus frequentadores (DOTTI, 2006, p. 399407). Já na dedicatória dos Discursos sobre a primeira década de Tito Lívio, Maquiavel demonstra o apreço que ele tinha por seus jovens amigos. Depois de ter sido destituído de seu cargo e jogado na prisão, discutir questões que lhe interessavam com jovens ávidos de escutá-lo e de compreender o mundo transformado que tinham diante dos olhos, foi uma forma de voltar à vida pública que ele tanto amava (Idem, p. 403).

Se considerarmos que muitos dos jovens que frequentavam os Orti Oricellari acabaram se envolvendo, em 1522, 
em uma conspiração contra os Médici, podemos ser levados a crer que Maquiavel exercia sobre eles uma verdadeira liderança política. ${ }^{6}$ No entanto, essa é uma percepção que pode enganar. De fato, Maquiavel era querido por muitos jovens (DIONISOTTI, 1980, p. 147), mas também era criticado por alguns, que estavam longe de partilhar suas convicções republicanas. Alguns chegaram a escrever poemas em seu louvor (Idem, p. 122); outros como Donato Gianotti, foram verdadeiros continuadores de sua obra (BIGNOTTO, 2013, p. 201-218). Mas isso não deve mascarar o conflito que se escondia por trás de uma relação amistosa. A prova é que Maquiavel se opôs à conjuração de 1512 e não obteve cargo algum quando a república foi restaurada em 1527.

Para compreender as relações que Maquiavel entretinha com seus jovens amigos, é necessário entender a natureza das reuniões e qual era o público dos Orti Oricellari. As reuniões haviam começado ainda no tempo de Bernardo Rucellai no começo do Cinquecento. Nessa época elas eram frequentadas pela facção aristocrática, que se opunha ao governo de Soderini. Só esse fato já explica porque Maquiavel, que era um fiel servidor da República florentina até 1512, não podia ter sido membro do grupo. Ele seria introduzido no círculo florentino em sua segunda fase (1513-1522), depois da morte de Rucellai em 1514, para ler algumas partes de seus escritos daqueles anos. Esse simples fato serve de explicação para a importância desse fórum para o estudo da questão que nos interessa. Seria incorreto, no entanto, imaginar que nos Orti Oricellari só se discutia sobre questões políticas e se elaboravam planos de

\footnotetext{
${ }^{6}$ Os documentos de que dispomos sobre a conspiração foram publicados em: "DOCUMENTI della congiura fatta contro il Cardinale Giulio de' Medici nel 1512”. Giornale storico degli Archivi Toscani, III, 1859.
} 
oposição aos Médici. Uma parte importante dos participantes era próximo da família que governara Florença por tanto tempo no século anterior e estava muito mais interessada em debater temas literários e artísticos do que em conspirar contra os governantes que ocupavam o poder. Nesse grupo se incluíam, claro, a família Rucellai, Luigi Alamanni, Zanobi Buondelmonti, Battista della Palla, Alessandro de' Pazzi e Filipo de' Nerli. Ao lado desses membros pertencentes à aristocracia florentina se encontravam membros dos extratos sociais intermediários como Antonio Brucioli, Donato Giannotti, ou ainda o filósofo Francesco Diacceto (ALBERTINI, 1970, p. 68-69). A composição mesma das reuniões explica por que as discussões literárias eram muito mais importantes do que as de cunho diretamente político (Idem, p. 69).

Para compreender a "conversão" dos Orti Oricellari em núcleo da resistência à dominação dos Médici, é necessário levar em conta o jogo político pelo qual os Médici enterraram os sonhos dos ottimati de voltar a ter uma posição dominante na cena política, levando-os à exasperação (Ibid., p 70). Bernardo Rucellai já exprimia sua desilusão em 1513 diante das manobras dos novos senhores para se assegurar de todos os mecanismos de poder de Florença (ALBERTINI, 1970, p. 72). Essa mistura de aspirações perdidas, de estudos humanistas e da influência de Maquiavel produziu uma atmosfera propícia à propagação das ideias republicanas, que Albertini resume muito bem quando afirma:

Eis como se apresentava a atmosfera política e cultural dos Orti Oricellari: reuniões entre os membros das famílias mais importantes da cidade, sobretudo dos jovens; debates literários; críticas contra o governo; a experiência do mundo antigo por meio do modelo 
romano; o desejo de se afirmar na cena política; retomada da ideia de uma milícia popular (Idem, p. 73).

Todos esses elementos não transformavam, é claro, os participantes dos debates em um "partido" com claros objetivos políticos. Alguns, como Lodovico Alamanni, permaneceram ligados aos Médici, outros continuaram a sustentar o sonho de fazer de Florença mais uma vez uma cidade republicana. No interior desse campo havia diversas tendências. De um lado se encontravam os partidários de Savonarola, que ainda nutriam a ideia de uma república ligada aos sonhos milenaristas do frade. De outro lado, havia por exemplo, os aristocratas que, no entanto, aceitavam a participação popular nos negócios da cidade. Havia ainda os republicanos de talhe popular, como o próprio Maquiavel. O público que escutou o Secretário florentino nos Orti Oricellari entre 1516 e 1522 era variado e conflituoso, mas ofereceu a Maquiavel um terreno fértil no qual ele pôde expor suas ideias e conquistar novos "leitores" (ADVERSE, 2009).

Para continuar nossas análises vamos nos servir dos escritos de Antonio Brucioli. ${ }^{7}$ Filho dos extratos intermediários da sociedade florentina, desde muito cedo Brucioli se ligou aos jovens aristocratas que sonhavam com a reforma do Estado Florentino. Amigo de Luigi Alamanni, amante da filosofia, discípulo do filósofo Diacceto, ele participou da conjuração de 1522 e, por isso, foi obrigado a se exilar, depois do fracasso da mesma. Os Dialogi que nos interessam aqui foram redigidos inicialmente em Florença, mas tiveram sua redação terminada em Lion, na França. Sua primeira edição surgiu em Veneza em 1526 (BRUCIOLI, Dell stato dell'uomo)

7 Utilizamos aqui a primeira edição de seus escritos (BRUCIOLI, 1526). Para um estudo do conjunto de seus escritos ver: Spini (1940); Brucioli (2008). 
Os Dialogi testemunham a variedade dos interesses filosóficos do autor. Neles encontramos, ao lado das discussões políticas, toda uma série de questões metafísicas que galvanizavam a atenção de muitos jovens italianos do período (PROCACCI, 1965, p. 23-47). O primeiro "diálogo" trata da condição humana em geral. Nele o autor sublinha o fato de que a razão faz do homem um ser superior a todos os outros (BRUCIOLI, Dialogi della morale philosophia, f. I-III). É fácil identificar nele a influência do platonismo florentino, ao qual o autor estava filiado e, mais particularmente, a presença do pensamento de Pico della Mirandola. ${ }^{8}$ Aparecem também argumentos que, segundo Gilbert, haviam sido mobilizados antes pelas elites políticas florentinas do começo do século, o que não é de se estranhar dado o fato já mencionado de que ele foi um frequentador assíduo do Orti Oricellari (GILBERT, F., 1970, p. 17-51). No texto, Brucioli procura mostrar que a razão não serve apenas para guiar os homens em seus negócios materiais, mas que também permite a criação de formas políticas desenvolvidas, que mostram a verdadeira superioridade humana sobre todos os animais (BRUCIOLI, Dialogi della morale philosophia, f. XXI). Essa mistura de considerações de ordem antropológica e de observações políticas não é fruto de uma confusão na argumentação do autor, mas o sinal da influência dos clássicos sobre seu pensamento e da vontade de utilizá-los para compreender seu próprio tempo. Na verdade, Brucioli recorre com frequência à autoridade de autores como Platão e Aristóteles para fundamentar suas afirmações, como se recorresse a instrumentos que poderiam guiá-lo no difícil caminho da verdade.

${ }^{8}$ Conferir especialmente os trabalhos de Valcke (2005); Safa (2001). 
Encontramos um exemplo dessa abordagem eclética dos problemas em seu diálogo político mais importante, o Della Republica. O diálogo começa com a crítica da tirania que reina em Florença, que o autor chama de Cartago. Na esteira das considerações dos humanistas do século XV e do pensamento de Maquiavel, ele fala em seguida das milícias e afirma que elas são a garantia da superioridade das repúblicas bem armadas sobre todas as outras formas de governo. Para provar esse fato, ele procura refutar os argumentos dos que viam nas milícias de cidadãos um risco para a segurança interna das cidades (BRUCIOLI, Dialogi della morale philosophia, f. XX). Para dar mais força ao seu raciocínio, Brucioli procura ligar seu pensamento àquele dos antigos, fazendo referência à ideia de que todo corpo precisa de uma alma para funcionar (Idem, f. XXII-XXIII). Se a herança humanista é evidente nessa passagem do texto, também é inegável que o autor foi marcado pelo platonismo, que tivera um grande impulso em Florença depois das traduções feitas por Marsilio Ficino. Essa observação não implica, no entanto, uma crença na submissão de Brucioli a todos os ensinamentos de Platão. Ao contrário, ele se mostra, por exemplo, um crítico feroz da teoria dos bens comunitários (Ibid., f. XXI).

No que diz respeito aos tópicos mais diretamente políticos, a influência de Maquiavel se faz sentir de maneira mais evidente. Comentando as formas de governo, ele diz:

Vejamos agora quais são as boas repúblicas que existiram ou que podem existir e não aquelas que foram imaginadas e que não podem existir pois são mais próximas da imaginação dos poetas do que da multiplicidade das qualidades humanas (BRUCIOLI, Dialogi della morale philosophia, f. XX). 
Em que pese o fato de que o trecho citado contém uma referência direta ao décimo quinto capítulo d'O Príncipe, não podemos ser levados pela ideia de que o autor era um discípulo totalmente fiel às ideias de seu mestre. No momento de discorrer sobre sua ideia de que a república é a forma ideal de governo para Florença, ele busca apoio em Aristóteles, e não em Maquiavel.

Inicialmente Brucioli retoma a ideia aristotélica de que os homens são naturalmente animais políticos (Idem, f. XXV), para em seguida mostrar que a república mais estável é aquela governada pelos cidadãos das camadas intermediárias da sociedade, os que formam a classe média no pensamento aristotélico (mediocri) (Ibid., fXXVII). Para chegar a essa conclusão, ele parte de uma crítica à Platão. Mas seríamos injustos com nosso autor se víssemos em sua démarche o simples efeito de uma vontade de exibição de erudição. O que ele visa, por meio de um debate recheado de alusões ao passado literário e filosófico, é mostrar que a igualdade entre os cidadãos de Florença, ou pelo menos uma divisão equilibrada do poder, era a única solução razoável para os problemas que afligiam a cidade. A prova do que estamos dizendo é que ele se engaja em uma longa discussão sobre a melhor constituição para Florença, depois de ter afirmado que ela deveria estar alicerçada na "classe média" (DIONISITTI, 1980, p. 97).

Procuremos agora precisar os laços que uniam o pensamento de Brucioli àquele de Maquiavel. Inicialmente é possível identificar a influência do Secretário florentino sobre os jovens que frequentavam os Orti Oricellari pela análise dos temas que estavam no centro das preocupações de Brucioli. De fato, constatamos que um bom número de questões, que dominam os Discorsi de Maquiavel (1997) está presente nos 
Dialogi de Brucioli. A repetição dos temas é tal que não há lugar para se acreditar em simples coincidência, sobretudo quando observamos que algumas considerações de Maquiavel sobre a história italiana aparecem reproduzidas no texto dos Dialogi. Mas o fato de que Brucioli retoma questões tratadas por Maquiavel e com as quais tomou contato nas reuniões nos Jardins dos Rucellai, não quer dizer que ele partilhasse as mesmas ideias quanto à solução dos problemas analisados. Tomemos, por exemplo, a questão do melhor regime. Maquiavel, como Brucioli, aborda esse tema do ponto de vista da tradição do pensamento político. Ambos concordam que a república é o melhor dos regimes, mas Brucioli não hesita em sugerir que a imitação do passado é o melhor caminho para a implantação de um regime misto. Maquiavel também fala em imitação logo no começo dos Discorsi, mas, antes de mais nada, ele procura mostrar que imitar o passado é uma das coisas mais difíceis de se realizar e que os homens de seu tempo estavam muito longe de saber como fazê-lo (MAQUIAVEL, 1997, p. 196). Brucioli sabia que os homens devem agir no interior da cidade para construir a forma de governo que ele considera como ideal, o que ele parece deixar de lado é o fato de que o simples recurso às autoridades do passado é ineficaz para vencer os desafios postos a toda ação política num quadro tão conturbado quanto era o de sua cidade. Para ele, havia uma continuidade entre o passado e o presente que permitia pensar a ação política como o resultado de uma vontade que escolhe seu caminho à luz do que aprende com a tradição. Como autor renascentista, ele levava em conta o poder da fortuna e sua capacidade de impedir os homens de trilhar os caminhos que escolheram em algumas situações históricas precisas. Mas, em seu cálculo de 
forças, ele tendia a privilegiar o poder da livre escolha diante da força de impedimento da fortuna.

Assim, se ele parece apreciar a abordagem realista de Maquiavel da política, ele se mostra pouco capaz de seguir até o fim as exigências teóricas suscitadas pelo desenvolvimento argumentativo de Maquiavel (PROCACCI, 1965, p. 145). Para ele, como para muitos de seus amigos "republicanos", existe um laço entre o saber e a ação, que Platão teria revelado, que serve de guia para os atores políticos voltados para a procura da melhor forma de governo. Escapava-lhe, por exemplo, a constatação feita por Maquiavel da indeterminação fundamental de toda ação política. Da mesma maneira, o papel que o Secretário florentino atribuía à fortuna no desenrolar dos acontecimentos parecia-lhe exagerado. Para Brucioli, a ação podia se resumir na repetição dos gestos dos grandes atores do passado e, por isso, ele pensava em Brutus quando se lançou na Conspiração de 1522. Para Maquiavel, ao contrário, toda ação significa uma abertura para o indeterminado, o que faz com que a fortuna seja sempre um operador a ser levado em conta por aqueles que desejam transformar a realidade política. Talvez por isso, ele tenha se negado a participar da conspiração contra os Médici, que ele pensava estar destinada ao fracasso, e que levou tanto de seus jovens leitores ao exílio (DOTTI, 2006, p. 492-495).

As diferenças entre Maquiavel e Brucioli permitem-nos aprofundar nossa compreensão das relações entre ele e seus jovens leitores e frequentadores dos Orti Oricellari. O recurso à tradição era um ponto importante de contato entre as duas gerações, mas a maneira de apreciar esse recurso era bem diferente. Para os jovens sedentos de novas maneiras de compreender a política, Maquiavel abria um caminho inovador, 
mas que deveria ser percorrido ao lado das muitas certezas oferecidas pela tradição. Para Maquiavel, dialogar com o passado era essencial, mas como dizia n'O Príncipe, era preciso também incorporar o estudo e a experiência das "coisas modernas". Os jovens como Brucioli tinham plena consciência da importância do contexto em que viviam e dos desafios que os esperavam, mas não se mostravam capazes de mergulhar no universo revolucionário proposto por Maquiavel. Escutando-o expor suas ideias e muitos dos capítulos dos Discorsi, eles foram tomados de admiração, expressa em muitos textos escritos nos anos seguintes ao encontro com o Secretário florentino, mas nem sempre demonstraram querer correr os mesmos riscos na teoria que aceitaram correr na prática política. Maquiavel, ciente talvez da dificuldade de expor um pensamento político revolucionário para sua época, serviu-se do passado para ganhar a atenção de seus jovens e primeiros leitores, mas viu ao mesmo tempo fracassar a tentativa de mudar integralmente sua maneira de pensar a política. Na verdade, nem mesmo pensadores que o conheceram pessoalmente, e aprofundaram alguns aspectos teóricos de suas obras, como foi o caso de Donato Giannotti e a maneira crítica de Francesco Guicciardini ${ }^{9}$, demonstraram ter compreendido inteiramente o alcance de seu pensamento. O importante é que com seus primeiros e jovens leitores começou a história da recepção de uma obra que está longe de ter terminado. Seus primeiros e jovens leitores abriram uma trilha que continuamos a seguir quando nos interrogamos sobre a pertinência de seu pensamento para seu tempo e para o nosso.

${ }^{9}$ Ver a respeito dessa questão: Bignotto (2006, p. 162-192). 


\section{Referências}

ALAMANNI, Lodovico. "Sopra il fermare lo stato di Firenze nella devozione de' Medici”. In: ALBERTINI, Rudolf von. Firenze dalla Repubblica al Principato. Torino: Einaudi, 1970.

ALBERTINI, Rudolf von. Firenze dalla Repubblica al Principato. Torino: Einaudi, 1970.

ADVERSE, Helton. Maquiavel. Política e Retórica. Belo Horizonte: Editora da UFMG, 2009.

ANZILOTTI, A. La crise costituzionale della Repubblica Fiorentina. Roma: Multigrafica Editrice, 1969. p. 59.

BIGNOTTO, Newton Bignotto. Republicanismo e Realismo. Um perfil de Francesco Guicciardini. Belo Horizonte: Editora da UFMG, 2006.

. "Donato Giannotti e o problema do regime misto". In: ADERSE, Helton (Org). Filosofia Política no Renascimento Italiano. São Paulo: Annablume, 2013.

BRUCIOLI, Antonio. Dialogi della morale philosophia. Venezia: G. di Gregori, 1526.

- "Humanisme et évangélisme entre réforme et contre-réforme." In: Actes du colloque de Tours, 20-21 mai 2005, sous la direction de Elise Boillet. Paris: Honoré Champion, 2008.

. "Dell stato dell'uomo". In: Dialogi della morale philosophiai. F I. 
DIONISOTTI, Carlo. Machiavellerie. Torino: Einaudi, 1980.

DOCUMENTI DELLA CONGIURA FATTA CONTRO IL CARDINALE GIULIO DE MEDICI NEL 1512. In: Giornale storico degli Archivi Toscani, III, 1859.

DOTTI, Ugo. La révolution Machiavel. Grenoble: Éditions Jérome Million, 2006.

GILBERT, A. Machiavelli's Prince and its forerunners. Burham: Duke University Press, 1938.

GILBERT, Felix Gilbert. Machiavelli e Guicciardini. Pensiero politico e storiografia a Firenze nel Cinquecento. Torino: Einaudi, 1970.

LEFORT, Claude. Le travail de l'oeuvre. Machiavel. Paris: Gallimard, 1972.

MACHIAVELLI, Niccolò. Lettere. Milano: Feltrinelli, 1981.

. Discorsi sopra la prima deca di Tito Livio. In: Opere. Torino: Einaudi-Gallimard, 1997, vol I.

MERLEAU-PONTY. Léloge de la philosophie. Paris: Gallimard, 1968.

PANCERA, Gabriel. Maquiavel entre Repúblicas. Belo Horizonte: Editora da UFMG, 2010.

PROCACCI, Giuliano Procacci. Studi sulla fortuna del Machiavelli. Roma: Istituto Storico italiano per l'età moderna e contemporanea, 1965. 
SAFA, Karine. L'humanisme de Pic de la Mirandole. Paris: J, Vrin, 2001.

SILVANO, Giovanni. Vivere civile e Governo misto a Firenze nel primo cinquecento. Bologna: Patron Editore, 1985.

SPINI, G. Tra Rinascimento e Riforma. Antonio Brucioli. Roma: La Nuova Italia Editrice, 1940.

VALCKE, Louis. Pic de la Mirandole. Un itinéraire Philosophique. Paris: Les Belles Lettres, 2005. 